\title{
Aging and Physiological Changes of the Kidneys Including Changes in Glomerular Filtration Rate
}

\author{
Carlos G. Musso ${ }^{a} \quad$ Dimitrios G. Oreopoulos ${ }^{b}$ \\ ${ }^{a}$ Hospital Italiano de Buenos Aires, Buenos Aires, Argentina; ${ }^{b}$ University Hospital of Toronto, Toronto, Ont., Canada
}

\section{Key Words}

Senile renal changes $\cdot$ Glomerular filtration rate $\cdot$ Vascular dysautonomia - Sodium reabsorption - Potassium

secretion $\cdot$ Renal reserve

\begin{abstract}
In addition to the structural changes in the kidney associated with aging, physiological changes in renal function are also found in older adults, such as decreased glomerular filtration rate, vascular dysautonomia, altered tubular handling of creatinine, reduction in sodium reabsorption and potassium secretion, and diminished renal reserve. These alterations make aged individuals susceptible to the development of clinical conditions in response to usual stimuli that would otherwise be compensated for in younger individuals, including acute kidney injury, volume depletion and overload, disorders of serum sodium and potassium concentration, and toxic reactions to water-soluble drugs excreted by the kidneys. Additionally, the preservation with aging of a normal urinalysis, normal serum urea and creatinine values, erythropoietin synthesis, and normal phosphorus, calcium and magnesium tubular handling distinguishes decreased GFR due to normal aging from that due to chronic kidney disease.

Copyright @ 2011 S. Karger AG, Basel
\end{abstract}

\section{Introduction}

Several histological and physiological changes make the aged kidney different from the young one, and they may lead to a number of clinical conditions usually observed in the old population. In the following, we describe these changes and the clinical syndrome resulting from them.

\section{Structural and Physiological Senile Renal Changes}

Since the age of 30 years, a process of glomerular replacement by fibrous tissue - glomerulosclerosis - starts, affecting an increasing number of glomeruli with increasing age. The mesangium increases to nearly $12 \%$ by the age of 70, and microangiographic examination shows obliteration particularly of the juxtamedullary nephrons that is followed by the formation of a direct channel between afferent and efferent arterioles (i.e. aglomerular circulation) (table 1). Arterioles show subendothelial deposition of hyaline and collagen fibers that produce intimal thickening. In the small arteries, the intima is thickened due to proliferation of the elastic tissue, the media shows atrophy and there is dysfunction of the autonomic vascular reflex

\section{KARGER}

Fax +4161306 1234 E-Mail karger@karger.ch www.karger.com
Dr. Carlos Guido Musso

14 de julio 246

Temperley, BA 1834 (Argentina)

E-Mail carlos.musso@hospitalitaliano.org.ar 
Table 1. Senile hypofiltration: its mechanisms

Senile hypofiltration

Glomerulosclerosis

Mesangial expansion

Table 2. Senile renal vascular changes: its mechanisms

Renal vascular changes

Renal atherosclerosis

Vascular dysautonomy

Arteriole subendotelial hyalinosis

Aglomerular circulation

Table 3. Senile tubule-interstitial changes: its mechanisms

Tubule-interstitial changes

Tubular diverticuli

Tubular atrophy

Tubular fat degeneration

Reduced sodium reabsorption

Reduced potassium secretion

Interstitial fibrosis

Medulla hypotonicity (table 2). Renal tubules undergo fatty degeneration and irregular thickening of their basal membrane with increasing zones of tubular atrophy and fibrosis $[1,2]$. In a recent study, Rule at al. [3] have shown that the prevalence of glomerulosclerosis in healthy people (kidney donors) was 2.7 , $16,44,58$, and $73 \%$ for those very young, young, adult, old and very old, respectively. These authors found that neither kidney function nor chronic kidney disease (CKD) risk factors could explain the strong association between age and glomerulosclerosis in healthy adults.

As a result of the above anatomical changes, there is a decrease in the glomerular filtration rate (GFR) and the effective renal plasma flow (ERPF); the latter decreases disproportionally more than GFR - 10\% per decade from $600 \mathrm{ml} / \mathrm{min} / 1.73 \mathrm{~m}^{2}$ in youth to $300 \mathrm{ml} / \mathrm{min} / 1.73 \mathrm{~m}^{2}$ by the age of 80 . Therefore, the filtration fraction, which is the ratio of GFR/ERPF, usually increases in the elderly since the denominator (ERPF) is disproportionately lower than the numerator (GFR) $[1,2,4]$.

Measurement of the GFR with ${ }^{51} \mathrm{Cr}$-EDTA confirms that healthy elderly individuals have a lower GFR than young subjects. At the third decade of life, GFR peaks at approximately $140 \mathrm{ml} / \mathrm{min} / 1.73 \mathrm{~m}^{2}$, and from then on, progressively declines to an approximate rate of $8 \mathrm{ml} /$ $\mathrm{min} / 1.73 \mathrm{~m}^{2}$ per decade. This fall in creatinine clearance (Ccr) is accompanied by a decrease in creatinine production (senile sarcopenia), and consequently serum creatinine does not increase with the progressive decrease in GFR [5]. It may be better if GFR is expressed after correcting its value for body surface area, especially in the elderly in whom body surface area is usually reduced compared with the young [4]. After Kimmel et al. [34] demonstrated that old people who were on a high-protein diet maintained normal GFR, it has been hypothesized that 'normal' GFR observed in some elderly could be the consequence of increased protein intake that is followed by glomerular hyperfiltration $[5,6]$. It has been reported that in approximately one third of old people the GFR does not decrease with age [6], but this observation has not been confirmed by subsequent publications.

Twenty-four-hour urinary sodium output and fractional excretion of sodium are significantly greater in old people because thick ascending loop of Henle sodium reabsorption and basal plasma concentrations of renin and aldosterone, and the response to their stimuli are diminished in old age. As GFR declines with age and the amount of filtered sodium is lower than in young subjects, a salt load given to an aged person takes longer to eliminate. Additionally, since there is medullary hypotonicity in old subjects, they exhibit an inability to maximally concentrate the urine. Moreover, urinary dilution capability is also decreased in aged people. Regarding the senile renal tubular handling of potassium and urea, potassium secretion and urea reabsorption are both reduced in this aged group (table 3) [7, 8].

\section{Senile Decrease in GFR Differs from That in Chronic Renal Disease}

It is important to emphasize that even though the aged kidney has a decreased GFR, it differs in many ways from that in patients with chronic renal failure. Thus, healthy very old persons (older than 85) and patients with CKD (stage 3 ) share two main physiological characteristics: a similarly low GFR (about $50 \mathrm{ml} / \mathrm{min}$ / $1.73 \mathrm{~m}^{2}$ ), and a diminished ability for salt and water reabsorption from the renal tubule. However, despite these similarities, the aged kidney and the chronically damaged one differ markedly in a number of physiological aspects described below [9]: 
- Proximal tubular function is preserved in the healthy oldest old and their serum erythropoietin and hemoglobin levels are normal. Conversely, anemia secondary to a low serum erythropoietin secretion is one of the main characteristics in CKD patients [9-11].

- Even though the fractional excretion (FE) of urea is increased in both settings, serum urea level is normal in the elderly while it is increased in chronic nephropathy $[9,12,13]$.

- Serum levels and FE of calcium, magnesium and phosphorus are normal in the healthy very old population, while CKD patients usually have increased FE of these substances, in the presence of normal magnesium, low calcium and high phosphorus serum levels. Parathyroid hormone and active vitamin D levels are normal in the healthy oldest old, while the former is increased and the latter is decreased in the CKD population [9, $10,13-15]$.

- FE of potassium increases as GFR decreases under the influence of the aldosterone hormone in patients with CKD. However, the FE of potassium is relatively diminished in relationship to GFR in the healthy very old people. This phenomenon has been attributed to a relatively low serum aldosterone and aldosterone resistance in healthy very old people $[9,10,16,17]$.

- Urinalysis is normal in the healthy old people, that is they have neither hematuria nor proteinuria (lower than $0.3 \mathrm{~g}$ per day). However, the level of albuminuria may depend on the method of its assessment since if one uses the albumin-to-creatinine ratio to assess proteinuria, one may obtain a higher value due to the lower urinary creatinine excretion in the elderly [9].

\section{Creatinine Renal Handling in the Elderly}

Classically, it has been described that renal creatinine excretion in humans is the result of two physiological processes: glomerular filtration and proximal tubular secretion [12]. However, there are certain physiological situations, such as in the case of healthy newborns and premature babies, and dehydrated adults, in which tubular creatinine reabsorption has been documented [18-23]. Despite the finding of a classical study by Rowe et al. [21] that showed that tubular secretion of creatinine did not change with normal aging, in a recent report, Musso et al. [22] documented a net creatinine reabsorption in the renal tubules of healthy old persons. It is possible that the senile tubular changes make the aged tubules more susceptible to creatinine reabsorption as it happens in new- borns, but in this case due to tubular immaturity $[1,2$, 24]. This creatinine reabsorption pattern turns into a secretion one in the setting of severe chronic renal disease [25].

\section{Renal Reserve in the Elderly}

Renal reserve is the capacity of the kidney to increase its basal GFR by at least $20 \%$ after an adequate stimulus, such as a protein load. An increase in plasma amino acid levels would result in an increase in the filtered load of amino acids at any given GFR and would provoke an increase in tubular amino acid reabsorption. Because amino acids and sodium are cotransported in the proximal tubule, proximal sodium chloride reabsorption would also increase, resulting in a decrease in sodium delivery to the distal tubule and macula densa, which induces the release of vasodilator autacoids, which lead to afferent arteriolar vasodilatation and a consequent increase in renal blood flow and GFR [26, 27]. Musso et al. [28] documented that renal reserve is preserved in healthy very old people, but its magnitude decreased significantly with aging.

\section{Glomerular Filtration Estimation in the Elderly}

In clinical practice, Ccr is estimated in the elderly using either the Cockcroft-Gault equation (CG) or the MDRD (modification of diet in renal disease) formula [29]. When applied to the elderly, each of these formulas has its advantages and disadvantages. CG underestimates Ccr in very old people, while MDRD has the advantage of not requiring the patient's weight for calculating GFR. Furthermore, Musso et al. [22] showed a poor correlation between GFR obtained by MDRD and the one measured by Ccr with cimetidine, which is a proxy of the GFR; conversely this study showed a good correlation between the Ccr obtained by CG and GFR measured by Ccr with cimetidine. MDRD estimated GFR (eGFR) and CG estimated Ccr overestimate true GFR in old people because of the senile lean mass reduction secondary to sarcopenia [29]. Keller [35] believes that the easiest formula for estimating GFR in people between 25 and 100 years old is the following one: $\mathrm{GFR}=130$ - age (in years) $\mathrm{ml} / \mathrm{min}$, but this has not been verified by direct comparison with creatinine clearance with cimetidine $[22,30]$. eGFR estimated by cystatin $\mathrm{C}$ is much less than eGFR estimated by the MDRD in the elderly and, therefore, using cystatin C eGFR increases the prevalence of CKD in community- 
based studies. Moreover, it has been demonstrated that in old persons with GFR lower than $60 \mathrm{ml} / \mathrm{min}$, cystatin eGFR is not superior to the calculations by the CG and MDRD formulas. Alvarez-Gregori et al. [31] have recently developed an easily available and inexpensive method (HUGE formula) for differentiating CKD from the decrease in GFR associated with the renal aging process and that resulting from a disease process. This formula includes hematocrit, blood urea and gender (HUGE), and diagnoses $\mathrm{CKD}$ regardless of the variables of age, blood creatinine, creatinine clearance, or eGFR. The HUGE formula is: $\mathrm{L}=2.51-(0.26 \times$ hematocrit $)+(0.12 \times$ urea $(\mathrm{mg} / \mathrm{dl})(+1.38$ if male). If $\mathrm{L}$ is a negative number, the individual does not have $\mathrm{CKD}$; if $\mathrm{L}$ is a positive number, CKD is present. The authors have demonstrated that the HUGE formula is more reliable than MDRD and CKDEPI, particularly in persons aged over 70 . However, this method has not been validated by other investigators yet.

\section{Clinical Consequences of Low GFR and Creatinine Reabsorption in the Elderly}

- A serum creatinine concentration of $1 \mathrm{mg} / \mathrm{dl}$ reflects a GFR of $120 \mathrm{ml} / \mathrm{min}$ in a 20 -year-old person and $60 \mathrm{ml} /$ min in an 80-year-old [6].

- Senile hypofiltration predisposes healthy old people to cardiac failure and to lung congestion if they receive a saline load [6].

- The dose of prescribed drugs must be adjusted to the senile GFR preferably calculated by the CG formula [32].

- In old people, low GFR differs from CKD because the GFR is the expected one for the age, as well as the fact that the GFR is stable over a period of 6-12 months. In addition, on urinalysis, low GFR shows neither glomerular hematuria nor significant proteinuria $(>0.30$ g/day) [6].

- Contrary to what happens in healthy young persons, a measured Ccr underestimates GFR in the healthy old individual [22].

- In acute renal failure secondary to dehydration in young people, blood urea level is increased with normal serum creatinine, a situation that normalizes with rehydration. The high serum urea level can be explained by the extensive urea tubular reabsorption induced by volume contraction. However, acute renal failure secondary to dehydration in old people usually shows an elevation not only of serum urea level but also of serum creatinine, and both altered values also normalize with rehydration. The latter observation can be explained by the documented difference in tubular creatinine handling (i.e. creatinine reabsorption) in old people compared to young patients [22, 33].

\section{Acknowledgment}

The authors wish to thank Prof. Dr. Juan F. Macías Núñez for his review of the manuscript and his useful editorial comments.

\section{Disclosure Statement}

The authors have no conflicts of interest to declare.

\section{References}

1 Silva FG: The ageing kidney: a review. I. Int Urol Nephrol 2005;37:185-205.

12 Silva FG: The ageing kidney: a review. II. Int Urol Nephrol 2005;37:419-432.

-3 Rule AD, Amer H, Cornell LD, Taler SJ, Cosio FG, Kremers WK, Textor SC, Stegall MD: The association between age and nephrosclerosis on renal biopsy among healthy adults. Ann Intern Med 2010;152:561-567.

4 Alvarez Gregori J, Musso C, Macias Núñez JF: Renal ageing; in Sastre J, Pamolona R, Ramón J (eds): Medical Biogerontology. Madrid, Ergon, 2009, pp 111-123.

\footnotetext{
5 Cockcroft DW, Gault MH: Prediction of creatinine clearance from serum creatinine. Nephron 1976;16:31-41.

-6 Musso CG: Geriatric nephrology and the 'nephrogeriatric giants'. Int Urol Nephrol 2002;34:255-256.

7 Lindeman RD, Tobin J, Shock NW: Longitudinal studies on the rate of decline in renal function with age. J Am Geriatr Soc 1985;33: 278-285.

8 Macías Núñez JF, Cameron S: Renal function in the elderly; in Cameron S (ed): Oxford Textbook of Clinical Nephrology. Oxford, Oxford University Press, 2006.
}

\9 Musso CG, Macías Nuñez JF, Oreopoulos DG: Physiological similarities and differences between renal aging and chronic renal disease. J Nephrol 2007;20:586-587.

10 Swartz R: Fluid, electrolyte, and acid-base changes during renal failure; in Kokko J, Tannen R (eds): Fluids and Electrolytes. Philadelphia, Saunders, 1996, pp 487-532.

11 Musso CG, Musso CAF, Joseph H, et al: Plasma erythropoietin levels in the oldest old. Int Urol Nephrol 2004;36:259-262.

12 Rennke H, Denker B: Renal Pathophysiology. Philadelphia, Lippincott, Williams \& Wilkins, 2007. 
13 Musso CG, Macías Nuñez JF: Renal physiology in the oldest old: the Sphinx remakes her question. Int Urol Nephrol 2005;37:653-654.

14 Musso CG, Alvarez Gregori JA, Macías Nuñez JF: Renal handling of uric acid, magnesium, phosphorus, calcium, and acid-base in the elderly; in Macías Núñez JF, Cameron S, Oreopoulos D (eds): The Aging Kidney in Health and Disease. New York, Springer, 2008, pp 155-171.

15 Plantalech L, Knoblovits P, Cambiazzo E, et al: Hipovitaminosis D en ancianos institucionalizados de Buenos Aires. Medicina 1997;57:29-35.

-16 Musso CG, Miguel R, Algranati L, et al: Renal potassium excretion: comparison between chronic renal disease patients and old people. Int Urol Nephrol 2005;37:167-170.

-17 Musso CG, Liakopoulos V, De Miguel R, et al: Transtubular potassium concentration gradient: comparison between healthy oldpeople and chronic renal failure patients. Int Urol Nephrol 2006;38:387-390.

18 Matos P, Duarte-Silva M, Drukker A et al: Creatinine reabsorption by the newborn rabbit kidney. Pediatric Research 1998;44: 639-641.

-19 Alt JM, Colenbrander B, Forsling ML, MacDonald A: Perinatal development of tubular function in the pig. Q J Exp Physiol 1984;69: 693-702.
20 Coulthard MG, Hey E, Ruddock V: Creatinine and urea clearances compared to inulin clearance in preterm and mature babies. Early Hum Dev 1985;11:11-19.

21 Rowe JW, Andres R, Tobin JD, Norris AH, Shock NW: The effect of age on creatinine clearance in men: a cross-sectional and longitudinal study. J Gerontol 1976;31:155-163.

-22 Musso CG, Michelángelo H, Vilas M, Reynaldi J, Martinez B, Algranati L, Macías Núñez JF: Creatinine reabsorption by the aged kidney. Int Urol Nephrol 2009;41:727731.

23 Sjöström PA, Odlind BG, Wolgast M: Extensive tubular secretion and reabsorption of creatinine in humans. Scand J Urol Nephrol 1988;22:129-131.

24 Zhou XJ, Laszik ZG, Silva FG: Anatomica changes in the aging kidney; in Macías Núñez JF, Cameron JS, Oreopoulos D (eds) The Aging Kidney in Health and Disease. New York, Springer, 2008 pp 39-54.

25 Musso CG, Michelangelo H, Vilas M, Martinez B, Bonetto A, Jauregui R, Algranati L: Renal creatinine handling in very old patients with chronic renal disease. Int Urol Nephrol (in press).

26 Musso CG, Reynaldi J, Imperiali N, Algranati L: Inhibition of renal reserve in chronic renal disease. Nephroprevention 2007;2 (electronic journal: www.nephroprevention.org).

-27 Hellerstein S, Berenbom M, Erwin P, Wilson N, DiMaggio S: Measurement of renal functional reserve in children. Pediatr Nephrol 2004;19:1132-1136.
28 Musso CG, Reynaldi J, Martinez B, Pierángelo A, Vilas M, Algranati L: Renal reserve in the oldest old. Int Urol Nephrol 2010 (in press).

29 Daugirdas J, Blake P, Ing T: Dialysis Handbook. Philadelphia, Kluwer, 2008.

30 Macías Nuñez JF, López Novoa JM; in Macías Núñez JF, Cameron S, Oreopoulos D (eds): Physiology of the Healthy Aging Kidney. The Aging Kidney in Health and Disease. New York, Springer, 2008 pp 93-112.

31 Alvarez-Gregori JA, Robles NR, Mena C, Ardanuy R, Macías Núñez JF: The value of a formula including haematocrit, blood urea and gender (HUGE) as a screening test for chronic renal insufficiency. JNHA (in press).

32 Bennet W: Geriatric Renal Pharmacology: Practical Considerations; in Friedman E, Oreopoulos D, Sands J (eds): Geriatric Nephrology: An Epidemiologic and Clinical Challenge. Postgraduated Education Course of the American Society of Nephrology. 2008:205-213.

33 Faber M, Kuppin W, Gopal Krishna, Narins $\mathrm{R}$ : The differential diagnosis of acute renal failure; in Lazarus JM, Brenner BM (eds): Acute Renal Failure. New York, Churchill Livingston, 1993 pp 133-192.

- 34 Kimmel PL, Lew SQ, Bosch JP: Nutrition, ageing and GFR: is age-associated decline inevitable? Nephrol Dial Transplant 1996; 11(suppl 9):85-88.

35 Keller F: Kidney function and age. Nephrol Dial Transplant 1987;2:382. 